D) Check for updates

Cite this: Dalton Trans., 2020, 49, 10523

Received 7th July 2020,

Accepted 8th July 2020

DOI: $10.1039 / \mathrm{d} 0 \mathrm{dt} 02406 \mathrm{f}$

rsc.li/dalton

\title{
Synthesis and reactivity of alkaline-earth stannanide complexes by hydride-mediated distannane metathesis and organostannane dehydrogenation $\dagger$
}

\author{
Louis J. Morris, ${ }^{a}$ Nasir A. Rajabi, (D) a Mary F. Mahon, ${ }^{a}$ lan Manners, (D) ${ }^{b}$ \\ Claire L. McMullin (iD *a and Michael S. Hill (iD *a
}

\begin{abstract}
The synthesis of heteroleptic complexes with calcium - and magnesium-tin bonds is described. The dimeric $\beta$-diketiminato calcium hydride complex, $[(\mathrm{BDI}) \mathrm{Ca}(\mu-\mathrm{H})]_{2}\left({ }^{\mathrm{Ca}}\right)$ reacts with $\mathrm{Ph}_{3} \mathrm{Sn}-\mathrm{SnPh}_{3}$ to provide the previously reported $\mu_{2}-\mathrm{H}$ bridged calcium stannanide dimer, $\left[(\mathrm{BDI})_{2} \mathrm{Ca}_{2}\left(\mathrm{SnPh}_{3}\right)(\mu-\mathrm{H})\right](3)$. Computational assessment of this reaction supports a mechanism involving a hypervalent stannate intermediate formed by nucleophilic attack of hydride on the distannane. Monomeric calcium stannanides, [(BDI)Ca(SnPh $\left.) \cdot \mathrm{OPPh}_{3}\right]\left(\mathbf{8} \cdot \mathrm{OPPh}_{3}\right)$ and [(BDI)Ca(SnPh 3$\left.) \cdot T M T H F\right](8 \cdot T M T H F, T M T H F=2,2,5,5$-tetramethyltetrahydrofuran) were obtained from I ${ }^{\mathrm{Ca}}$ and $\mathrm{Ph}_{3} \mathrm{Sn}-\mathrm{SnPh}_{3}$, after addition $\mathrm{OPPh}_{3}$ or TMTHF. Both complexes were also synthesised by deprotonation of $\mathrm{Ph}_{3} \mathrm{SnH}$ by $\mathrm{I}^{\mathrm{Ca}}$ in the presence of the Lewis base. The calcium and magnesium THF adducts, [(BDI)Ca( $\left.\left(\mathrm{SnPh}_{3}\right) \cdot \mathrm{THF}_{2}\right]\left(\mathbf{8} \cdot \mathrm{THF}_{2}\right)$ and [(BDI)Mg( $\left.\left(\mathrm{SnPh}_{3}\right) \cdot \mathrm{THF}\right](\mathbf{9} \cdot \mathrm{THF})$, were similarly prepared from $[(\mathrm{BDI}) \mathrm{Ca}(\mu-\mathrm{H}) \cdot(\mathrm{THF})]_{2}\left(\mathrm{I}^{\mathrm{Ca}} \cdot \mathrm{THF}_{2}\right)$ or $[(\mathrm{BDI}) \mathrm{Mg}(\mu-\mathrm{H})]_{2}\left(\mathrm{I}^{\mathrm{Mg}}\right)$ and $\mathrm{Ph}_{3} \mathrm{SnH}$. An excess of THF or TMTHF was essential in order to obtain 8.TMTHF, 8-THF 2 and 9.THF in high yields whilst avoiding redistribution of the phenyl-tin ligand. The resulting Ae-Sn complexes were used as a source of $\left[\mathrm{Ph}_{3} \mathrm{Sn}\right]^{-}$in salt metathesis, to provide the known tristannane $\mathrm{Ph}_{3} \mathrm{Sn}-\mathrm{Sn}(t-\mathrm{Bu})_{2}-\mathrm{SnPh}_{3}$ (11). Nucleophilic addition or insertion with $N_{,} N^{\prime}$-di-iso-propylcarbodiimide provided the stannyl-amidinate complexes, [(BDI)Mg\{(iPrN $\left.\left.)_{2} \mathrm{CSnPh}_{3}\right\}\right]$ (12) and [(BDI)Ca\{(iPrN $\left.\left.)_{2} \mathrm{CSnPh}_{3}\right\} \cdot \mathrm{L}\right]$ (13·TMTHF, 13-THF, L = TMTHF, THF). The reactions and products were monitored and characterised by multinuclear NMR spectroscopy, whilst for compounds $\mathbf{8}, \mathbf{9}, \mathbf{1 2}$, and $\mathbf{1 3} \cdot \mathrm{THF}$, the X-ray crystal structures are presented and discussed.
\end{abstract}

\section{Introduction}

Although Grignard's ubiquitous organomagnesium compounds have been widely used as synthetic reagents for over a century, the catalytic potential of alkaline-earth (Ae) reagents was largely overlooked until the past two decades. ${ }^{1,2}$ By analogy to well-established lanthanide(III)-based catalysis, ${ }^{3}$ $\mathrm{Ae}^{2+}$ centres participate in redox-neutral catalytic cycles that are assembled from fundamental steps such as polarised $2 \sigma-$ $2 \pi$ insertion- and $2 \sigma-2 \sigma$ metathesis. $^{2}$ In many cases, reactivity

\footnotetext{
${ }^{a}$ Department of Chemistry, University of Bath, Claverton Down, Bath, BA2 7AY, UK. E-mail:msh27@bath.ac.uk

${ }^{b}$ Department of Chemistry, University of Victoria, Victoria BC V8P 5C2, Canada $\dagger$ Electronic supplementary information (ESI) available: General synthetic experimental details, NMR spectra, X-ray diffraction analysis of compounds 8.0PPh 8.TMTHF, 8.THF 2 , 9.THF, 11, 12, 13.THF, details for the computational analysis and atomic coordinates of computed structures. CCDC 2003513-2003519. For ESI and crystallographic data in CIF or other electronic format see DOI: 10.1039/ dodt02406f
}

is better described by non-concerted processes involving attack of an Ae-bound nucleophile on a substrate, such as a silane, that is capable of expanding its coordination sphere. ${ }^{4-7}$ As such, the heavier alkaline earths ( $\mathrm{Mg}-\mathrm{Ba})$ are adept at mediating catalytic dehydrocoupling, ${ }^{5,8-15}$ hydrofunctionalisation, ${ }^{16-23}$ and even reductive hydrogenation reactions. ${ }^{24-26}$ We have previously reported the use of silylboranes to perform the catalytic 'disilacoupling' of amines and boranes; a non-dehydrogenative process thought to be dependent on Ae-mediated redoxneutral metathesis of $\mathrm{N}-\mathrm{H}$ and $\mathrm{Si}-\mathrm{B} \sigma$-bonds (Scheme 1, top). ${ }^{27}$ A model reaction between a $\beta$-diketiminato (BDI) magnesium butyl complex and the silylborane, $\mathrm{PhMe}_{2} \mathrm{Si}$-Bpin (Bpin = pinacolatoboryl), resulted in elimination of $n \mathrm{Bu}$-Bpin and isolation of the magnesium silanide complex, 1 (Scheme 1, bottom). ${ }^{27}$ Computational assessment has suggested that this reaction is best described by nucleophilic attack of a butyl group on the boron centre to provide a borate intermediate from which the silyl group is subsequently transferred to magnesium. ${ }^{28}$ Bis(pinacolato)diboron $\left(\mathrm{B}_{2} \mathrm{pin}_{2}\right)$, which contains a non-polar B-B $\sigma$-bond, was shown to react in a similar way with 

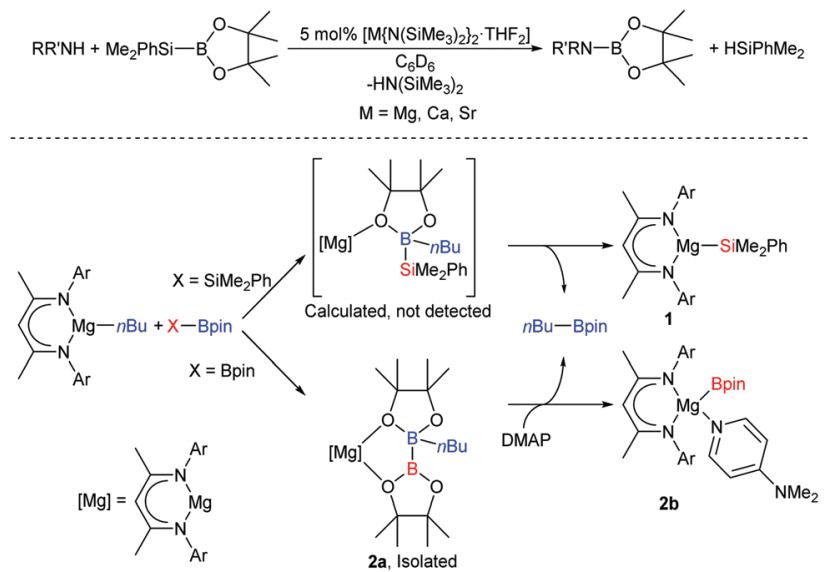

Scheme 1 Top, alkaline-earth mediated boron-nitrogen 'desilacoupling'; bottom, synthesis of magnesium silyl and boryl complexes from a nucleophilic alkyl-magnesium complex. ${ }^{27-29} \mathrm{Ar}=\mathrm{Dipp}=2,6$-di-isopropylphenyl, DMAP = 4-dimethylaminopyridine.

[(BDI)MgBu] to provide an isolable diboranate complex, 2a (Scheme 1, bottom). Treatment of $2 \mathrm{a}$ with 4-dimethylaminopyridine (DMAP) promoted heterolysis of the B-B bond and delivered the terminal magnesium boryl species, $\mathbf{2 b}$, which is a source of the nucleophilic [Bpin] ${ }^{-}$anion. ${ }^{29}$

The Ae-centred manipulation of boron-, silicon-, and organic substrates has, thus, received significant attention. In contrast, comparable reports of Ae-mediated reactivity suitable for the construction of catalytic cycles involving organostannanes, which could provide an attractive route towards materials such as polystannanes ${ }^{30,31}$ or act as sources of organostannane cross-coupling reagents, ${ }^{32,33}$ are lacking. The majority of published Ae-mediated organotin chemistry focusses on the irreversible, stoichiometric reaction between the group 2 element and organotin halides, distannanes and silastannanes. ${ }^{34-41}$ We recently reported that the BDI-calcium stannanide complexes $\mathbf{3}$ and $\mathbf{4}$ may be accessed through deprotonation of commercially available triphenylstannane by the soluble calcium hydride complex, $\mathbf{I}^{\mathrm{Ca}}$ (Scheme 2a). ${ }^{42}$ Crystallographically characterised examples of Ae-Sn bonds were previously limited to the calcium and magnesium complexes 5 and 6, and the barium species 7 (Scheme 2b). Compound $\mathbf{5}$ was readily prepared by the oxidative-addition of hexamethyldistannane to calcium metal, ${ }^{43}$ the synthesis of $\mathbf{6}$ and 7 utilised salt metathesis routes from group 1-metallated precursors. ${ }^{44-46}$ Neither of these strategies, however, is likely to be amenable to incorporation into catalytic cycles. Since the formation of $\mathbf{3}$ and $\mathbf{4}$ is redox neutral at calcium and generates $\mathrm{H}_{2}$ instead of insoluble salts as a by-product, therefore, it holds attractive potential for the development of Ae-based catalysts for processes such as hydrostannylation or stannane dehydrocoupling.

Distannanes are synthetically useful precursors to organotin radicals, ${ }^{47-53}$ as well as 1,2-distannylated alkanes and alkenes via transition metal-catalysed distannylation of alkenes and alkynes. ${ }^{54}$ Such organotin compounds are valuable cross-coupling reagents in organic synthesis. ${ }^{49,55}$ Although the heterogeneous reaction of distannanes with solid alkali $^{56}$ and alkaline-earth ${ }^{41,43}$ metals is well-known, the manipulation of distannanes by soluble s-block complexes has not been described. By analogy to the nucleophilic substitution-like process operative in the formation of $\mathrm{Mg}$-silyl and -boryl species $\mathbf{1}$ and $\mathbf{2 a / 2} \mathbf{b}$, we speculated that molecular calcium hydride and alkyl derivatives may react with $\mathrm{Ph}_{3} \mathrm{Sn}-$ $\mathrm{SnPh}_{3}$, providing an alternative route to nucleophilic calcium stannanide complexes. These investigations were motivated by the limitations encountered during our previously described synthesis of 3 and $4 .{ }^{42}$ Firstly, $\mathrm{I}^{\mathrm{Ca}}$ also promotes redistribution of the organotin substrate, culminating in the generation of homoleptic $\mathrm{SnPh}_{4}$ and (presumably) $\mathrm{SnH}_{4}$, the latter of which rapidly decomposes to give $\mathrm{Sn}^{(0)}$ and $\mathrm{H}_{2}$. Secondly, the strongly bound dimer of 3 retains a $\mu_{2}$-hydride ligand and the sub-

(a) Dehydrogenative $\mathrm{Ca}-\mathrm{Sn}$ bond formation
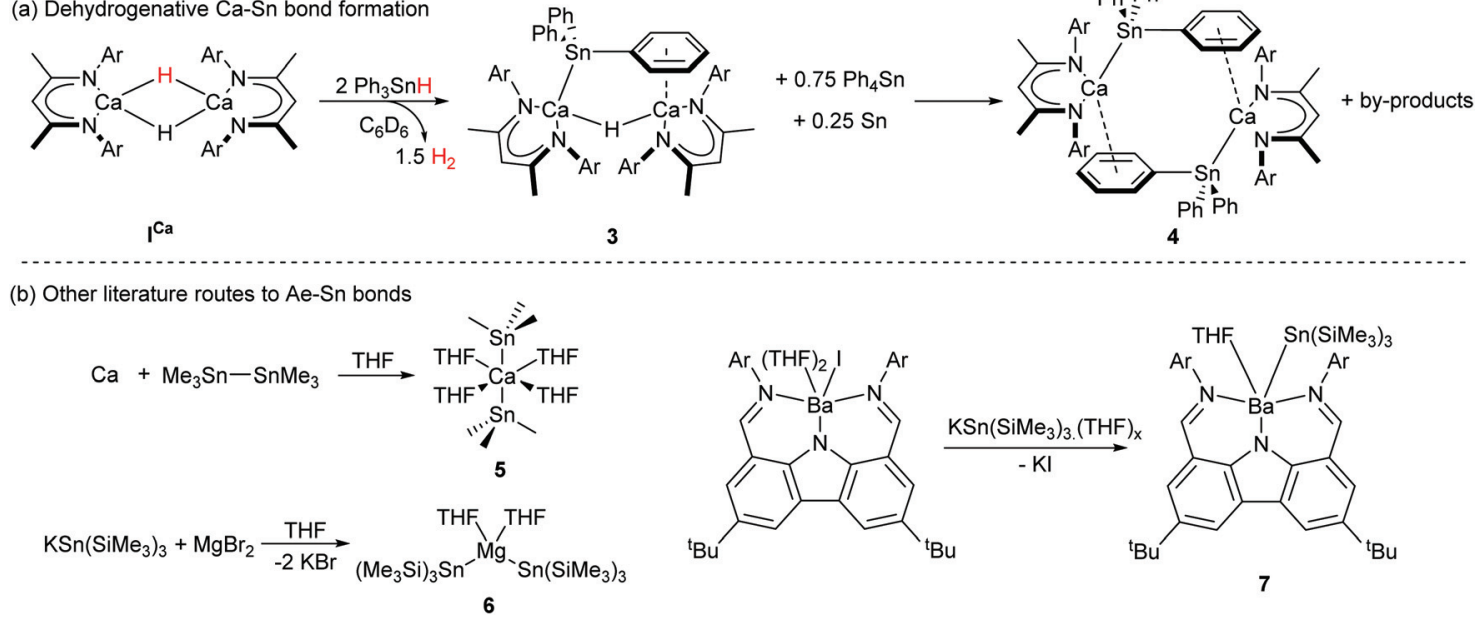

Scheme 2 (a) Dehydrogenative synthesis of $\mathrm{Ca}-\mathrm{Sn}$ bonded compounds 3 and $4 .^{42}$ (b) Crystallographically characterised literature compounds containing $\mathrm{Ae}-\mathrm{Sn}$ bonds prepared by salt-metathesis ${ }^{44-46}$ or oxidative addition routes. ${ }^{43} \mathrm{Ar}=2,6$-di-isopropylphenyl. 
sequent formation of $\mathbf{4}$ is low-yielding and slow, impeding any rational assessment of the reactivity of these unusual compounds. In this contribution, therefore, we describe the facile and high yielding synthesis of well-defined, monomeric Aestannanide complexes and a preliminary assessment of their nucleophilic reactivity.

\section{Results and discussion}

Reaction of $\mathrm{I}^{\mathrm{Ca}}$ with $\mathrm{Ph}_{3} \mathrm{Sn}-\mathrm{SnPh}_{3}$ and synthesis of compound 3

When $\mathbf{I}^{\mathrm{Ca}}$ was dissolved in $\mathrm{C}_{6} \mathrm{D}_{6}$ with an equimolar quantity of $\mathrm{Ph}_{3} \mathrm{Sn}-\mathrm{SnPh}_{3}$, the reaction mixture bubbled gently and darkened from pale-yellow to orange brown over the course of six hours. The respective $\mu$-hydride and $\mathrm{BDI}-\gamma-\mathrm{CH}$ proton resonances of $\mathrm{I}^{\mathrm{Ca}}$ at $\delta 4.27$ and $4.83 \mathrm{ppm}$ in the in situ ${ }^{1} \mathrm{H}$ NMR spectrum were replaced by two new singlets of relative intensity $2: 1$ at $\delta 4.75$ and $3.83 \mathrm{ppm}$. The latter signal displayed unresolved ${ }^{117 / 119} \mathrm{Sn}$ satellites with ${ }^{2} J\left({ }^{117 / 119} \mathrm{Sn}-{ }^{1} \mathrm{H}\right)=94 \mathrm{~Hz}$, while the corresponding ${ }^{119} \mathrm{Sn}\left\{{ }^{1} \mathrm{H}\right\}$ NMR spectrum revealed complete consumption of the distannane and the appearance of a signal at $\delta-139.8 \mathrm{ppm}$, which was accompanied by the generation of $\mathrm{Ph}_{4} \mathrm{Sn}(\delta-126 \mathrm{ppm}) .{ }^{57}$ These observations were consistent with the formation of the $\mu$-H-bridged dimeric calcium stannanide, 3, whilst the brown colouration was assigned to formation of colloidal tin. ${ }^{42}$ Although the slow formation of compound $\mathbf{4}$ was identified by its resonance at $\delta$ -158.5 ppm in the ${ }^{119} \mathrm{Sn}\left\{{ }^{1} \mathrm{H}\right\}$ NMR spectrum after a further five days at room temperature, complete conversion to this product was not obtained (Scheme 3).

\section{Computational and mechanistic investigation of $\mathrm{I}^{\mathrm{Ca}}$ mediated} $\mathrm{Ph}_{3} \mathrm{Sn}-\mathrm{SnPh}_{3}$ activation

In order to assess the mechanism of $\mathrm{Ph}_{3} \mathrm{Sn}-\mathrm{SnPh}_{3}$ activation, the reaction between $\mathrm{I}^{\mathrm{Ca}}$ and $\mathrm{Ph}_{3} \mathrm{Sn}-\mathrm{SnPh}_{3}$ was investigated by density functional theory (DFT, Fig. 1a, BP86 optimised, see $\mathrm{ESI} \dagger$ for full details of computational methodology). Although we cannot, at this juncture, discount the operation of competitive single electron-based processes, consistent with the reported reactivity of compound $\mathbf{I}^{\mathrm{Ca}}$ thus far, ${ }^{25}$ these calculations are suggestive of a metathesis-based reactivity. Following the initial formation of a van der Waals encounter complex $\left(\mathbf{A}, \Delta G=+8.7 \mathrm{kcal} \mathrm{mol}^{-1}\right)$, the distannane is subjected to nucleophilic attack by one of the $\mu_{2}$-hydride ligands $\left(\mathrm{H}^{\mathrm{a}}\right)$ via transition state $\mathbf{T S}_{\mathbf{A B}}$ (Fig. $1 \mathrm{~b}, \Delta G^{*}=+12.7 \mathrm{kcal} \mathrm{mol}{ }^{-1}$ ), at which the $\mathrm{Sn}^{\mathrm{a}}-\mathrm{Sn}^{\mathrm{b}}$ bond is marginally elongated from $2.85 \AA$ (calculated for $\mathrm{Ph}_{3} \mathrm{Sn}-\mathrm{SnPh}_{3}$ ) to $2.87 \AA$ A. Inspection of the $\mathrm{Ca}^{\mathrm{a}}-$ $\mathrm{H}^{\mathrm{a}}$ and $\mathrm{H}^{\mathrm{a}}-\mathrm{Sn}^{\mathrm{a}}$ bond lengths (2.30 $\AA$ and $2.14 \AA$, respectively) in the subsequent intermediate, $\mathbf{B}$ (Fig. 1c, $\Delta G=+5.2 \mathrm{kcal}$ $\mathrm{mol}^{-1}$ ), is suggestive of the transfer of $\mathrm{H}^{\mathrm{a}}$ to $\mathrm{Sn}^{\mathrm{a}}$ and the formation of a hypervalent stannate anion with a $\mathrm{Sn}^{\mathrm{a}}-\mathrm{Sn}^{\mathrm{b}}$ distance of $2.95 \AA$. The $\mathrm{Sn}^{\mathrm{a}}-\mathrm{Sn}^{\mathrm{b}}$ distance elongates to $3.55 \AA$ in the transition state $\mathbf{T S}_{\mathbf{B C}}\left(\Delta G^{\star}=+8.2 \mathrm{kcal} \mathrm{mol}^{-1}\right)$, facilitating cleavage of the stannate anion and concerted formation of a $\mathrm{Ca}^{\mathrm{a}}-\mathrm{Sn}^{\mathrm{b}}$ bond (distance in $\mathbf{T S}_{\mathbf{B C}}=2.24 \AA$ ) to give intermediate C $\left(\Delta G=+2.5 \mathrm{kcal} \mathrm{mol}^{-1}\right)$. Subsequent dissociation of $\mathrm{Ph}_{3} \mathrm{Sn}^{\mathrm{a}} \mathrm{H}^{\mathrm{a}}$ provides 3 , at $\Delta G=-5.2 \mathrm{kcal} \mathrm{mol}^{-1}$. Whilst the overall process is only moderately exergonic, the modest kinetic barrier is consistent with the room temperature reaction conditions. Meanwhile, rapid consumption of the resultant molecule of $\mathrm{Ph}_{3} \mathrm{SnH}$ provides a thermodynamic driving force, yielding $\mathrm{H}_{2}$ and a second molecule of 3 .

Experimental evidence in support of this mechanism was obtained by carrying out the analogous reaction between $\mathrm{Ph}_{3} \mathrm{Sn}-\mathrm{SnPh}_{3}$ and the $n$-hexyl-calcium complex $[(\mathrm{BDI}) \mathrm{Ca}(\mathrm{Hex})]_{2}$ (II). The relatively poor solubility of both substrates in $\mathrm{C}_{6} \mathrm{D}_{6}$ and the greater steric demand of the hexyl ligand compared to the hydride of $\mathbf{I}^{\mathbf{C a}}$ resulted in sluggish reaction kinetics. Nevertheless, after gentle heating to $40^{\circ} \mathrm{C}$ for 48 hours, the characteristic triplet corresponding to the $\alpha-\mathrm{CH}_{2}$ protons of II at $\delta-0.71 \mathrm{ppm}$ was all but absent from the ${ }^{1} \mathrm{H}$ NMR spectrum. Although this observation was accompanied by almost complete redistribution to $\left[(\mathrm{BDI})_{2} \mathrm{Ca}\right]^{58}$ as the only soluble BDI-containing product, a resonance at $\delta-98.2 \mathrm{ppm}$ in the corresponding ${ }^{119} \mathrm{Sn}\left\{{ }^{1} \mathrm{H}\right\}$ NMR spectrum revealed $\mathrm{Ph}_{3} \mathrm{Sn}(\mathrm{Hex})$ as the predominant tin-containing species. ${ }^{59}$ The absence of any unambiguously identifiable alkyl or stannyl-calcium species, such as a $n$-hexyl-containing analogue of 3, may be attributed to the likely low thermal stability of such intermediates. Formation of $\mathrm{Ph}_{3} \mathrm{Sn}(\mathrm{Hex})$, however, can be rationalised by attack of a calcium-bound $n$-hexyl-nucleophile on the distannane, with subsequent transfer of $\left[\mathrm{Ph}_{3} \mathrm{Sn}\right]^{-}$to calcium and elimination of $\mathrm{Ph}_{3} \mathrm{Sn}(\mathrm{Hex})$ (Scheme 4). Whereas the tetraorganostannane is inert towards further reactivity under these conditions, a similar reaction with $\mathbf{I}^{\mathrm{Ca}}$ would yield $\mathrm{Ph}_{3} \mathrm{SnH}$, which is rapidly deprotonated by a second molecule of $\mathbf{I}^{\mathrm{Ca}}$ to provide 3 .

\section{Synthesis and NMR characterisation of monomeric alkaline- earth stannanides 8 and 9.THF}

Compound 4 could only be accessed in low yields following fractional crystallisation of the crude products obtained from

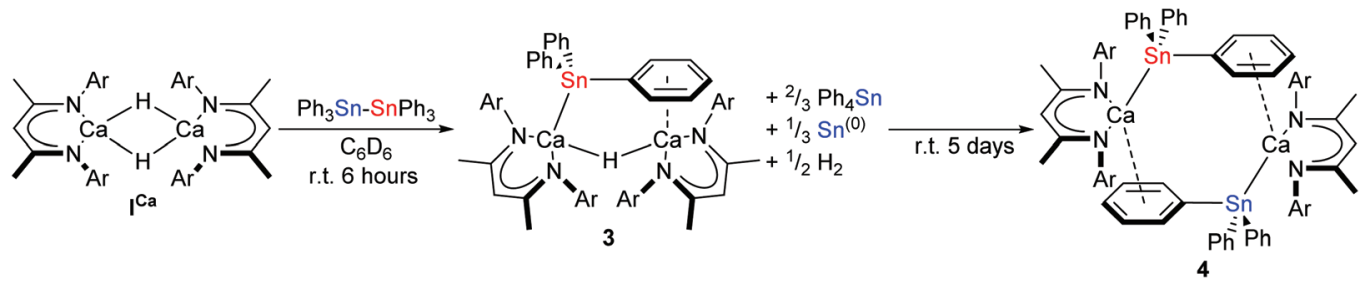

Scheme 3 Synthesis of 3 and 4 by reaction of $\mathrm{I}^{\mathrm{Ca}}$ with $\mathrm{Ph}_{3} \mathrm{Sn}-\mathrm{SnPh}_{3}$ in $\mathrm{C}_{6} \mathrm{D}_{6}$. Ar = 2,6-di-isopropylphenyl. 
(a) $\Delta \mathrm{G}\left[\mathrm{kcal} \mathrm{mol}{ }^{-1}\right]$

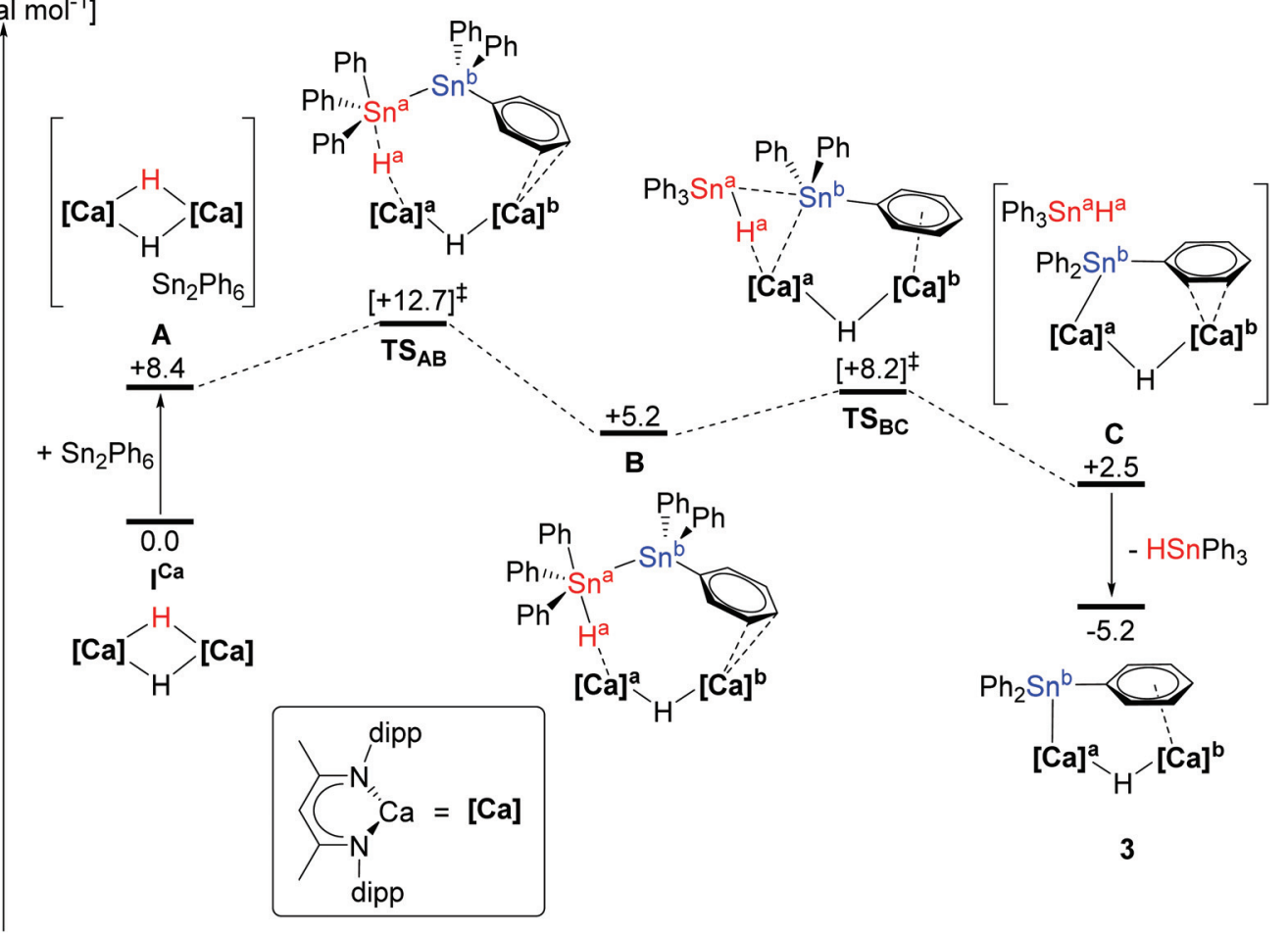

(b)

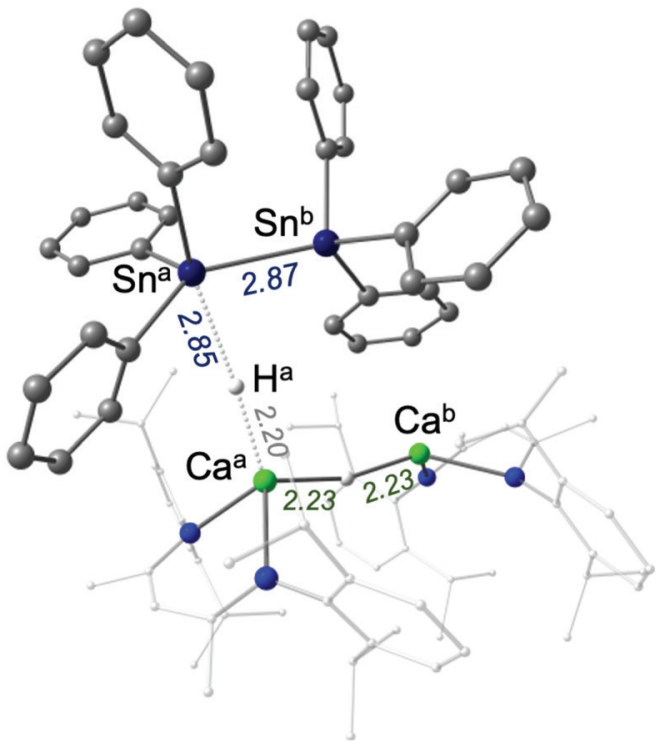

(c)

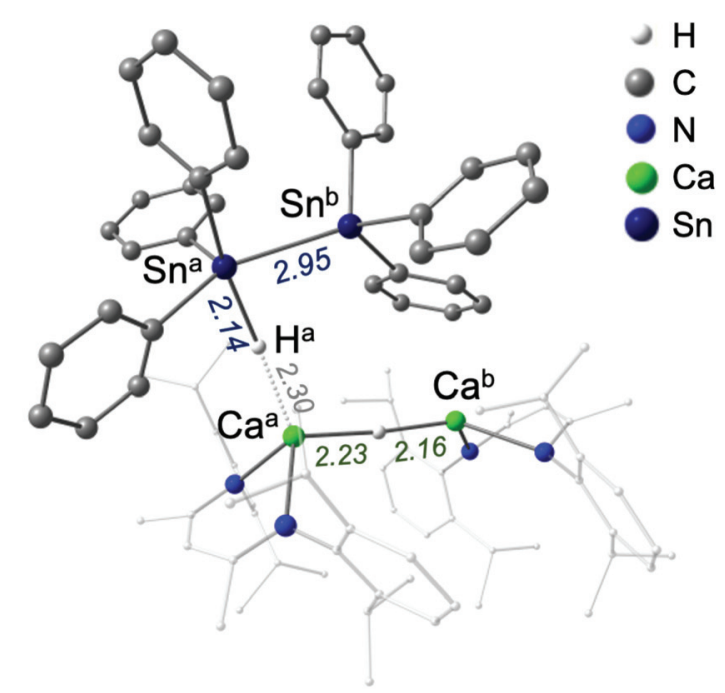

Fig. 1 (a) DFT calculated free energy surface (BP86-D3(BJ)-benzene/BS2//BP86/BS1, $\mathrm{kcal} \mathrm{mol}^{-1}$ ) for the reaction of $\mathrm{I}^{\mathrm{Ca}}$ with $\left(\mathrm{Ph}{ }_{3} \mathrm{Sn}\right)_{2}$; structures of (b) transition state $\mathrm{TS}_{\mathrm{AB}}$ and (c) intermediate $\mathrm{B}$. See $\mathrm{ESI} \dagger$ for full details.

reaction of I $^{\mathrm{Ca}}$ with $\mathrm{Ph}_{3} \mathrm{SnH}^{42}$ or $\mathrm{Ph}_{3} \mathrm{Sn}-\mathrm{SnPh}_{3}$. It was also anticipated that the $\mu_{2}$-hydride of 3 would provide a likely complication in subsequent efforts to assess the reactivity of the $\mathrm{Ca}-\mathrm{Sn}$ bond. With this in mind, we speculated that addition of a Lewis base would encourage fragmentation of the dimer, result in reaction of both hydride ligands, and provide a highyielding route towards a well-defined monomeric calcium stannanide. Similar strategies have previously been applied suc- cessfully to achieve, for example, the isolation of monomeric magnesium complexes comprising terminal hydride and boryl ligands. ${ }^{29,60,61}$

To this end, the reaction between $\mathbf{I}^{\mathrm{Ca}}$ and $\mathrm{Ph}_{3} \mathrm{Sn}-\mathrm{SnPh}_{3}$ was repeated and, after quantitative conversion of $\mathrm{I}^{\mathrm{Ca}}$ was ascertained by ${ }^{1} \mathrm{H}$ NMR spectroscopy, an equimolar equivalent of $\mathrm{Ph}_{3} \mathrm{PO}$ was added to the in situ generated solution of 3 (Scheme 5). Upon standing at room temperature for 24 hours, 


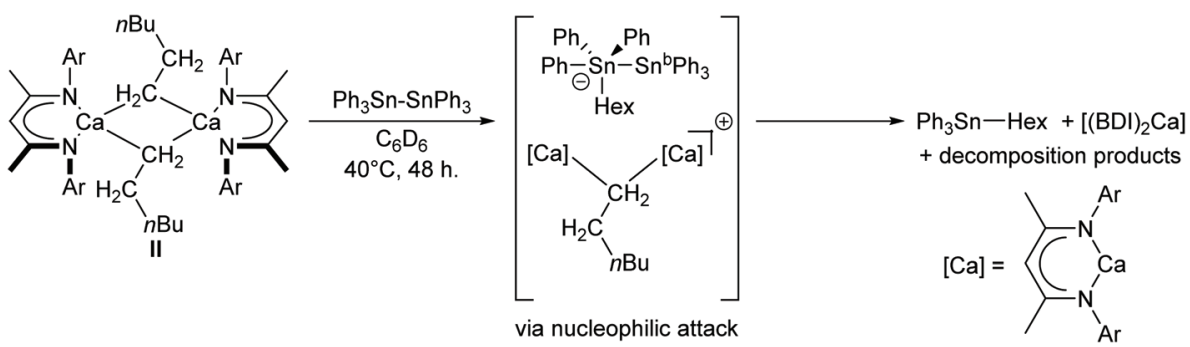

Scheme 4 Postulated mechanism for the reaction between II and $\mathrm{Ph}_{3} \mathrm{Sn}-\mathrm{SnPh}_{3}$. Ar = 2,6-di-isopropylphenyl.

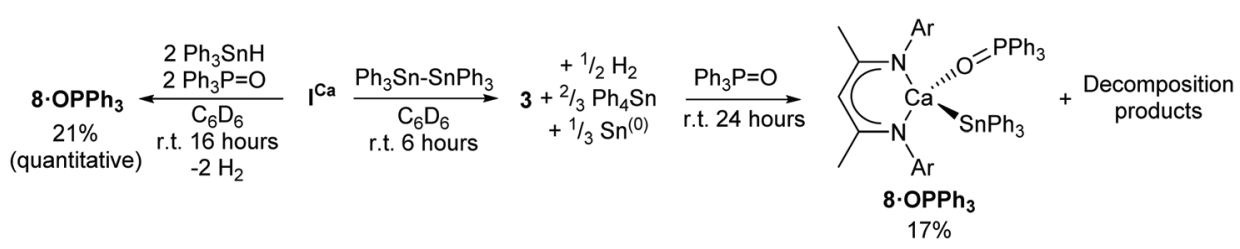

Scheme 5 Synthesis of the $\mathrm{Ph}_{3} \mathrm{PO}$-adduct, $8 . \mathrm{OPPh}_{3}$. Yields refer to unoptimised crystalline yield, those in parentheses refer to \% spectroscopic conversion determined by in situ ${ }^{1} \mathrm{H}$ NMR spectroscopy. $\mathrm{Ar}=2,6$-di-isopropylphenyl.

the reaction mixture took on an opaque dark-brown appearance and, in addition to several minor species, a major new BDI- $\gamma-\mathrm{CH}$ resonance was observed to have emerged at $\delta$ $5.23 \mathrm{ppm}$. The ${ }^{119} \mathrm{Sn}\left\{{ }^{1} \mathrm{H}\right\}$ NMR spectrum displayed a doublet at $\delta-146 \mathrm{ppm}$, whose coupling constant of $10 \mathrm{~Hz}$ is consistent with the sparse number of ${ }^{3} J\left({ }^{31} \mathrm{P}-{ }^{117 / 119} \mathrm{Sn}\right)$ coupling constants that have been reported. ${ }^{62,63}$ Notwithstanding some minor peaks at $\delta 88-89 \mathrm{ppm}$ and $71 \mathrm{ppm}$, consistent with this observation, the ${ }^{31} \mathrm{P}\left\{{ }^{1} \mathrm{H}\right\}$ NMR spectrum was free of evidence for any unligated phosphine oxide. The spectrum also comprised a major resonance at $\delta 36.4 \mathrm{ppm}$, which displayed unresolved ${ }^{117 / 119} \mathrm{Sn}$ satellites with an approximate coupling constant consistent with that observed in the ${ }^{119} \mathrm{Sn}\left\{{ }^{1} \mathrm{H}\right\}$ NMR spectrum. Recrystallisation of the crude product mixture from toluene/ hexane provided single-crystals of the monomeric $\mathrm{Ph}_{3} \mathrm{PO}-$ adduct $\mathbf{8 \cdot} \mathbf{O P P h}$ in low yield, from which the molecular structure was determined by X-ray diffraction analysis (Fig. 2a). Crystals of the known compound $\left[(\mathrm{BDI}) \mathrm{Ca}\left(\mathrm{OPPh}_{2}\right)\right]_{2}$ were also obtained from the same sample and identified from the unit cell-parameters determined by X-ray diffraction. ${ }^{64}$ This observation is consistent with the calcium hydride-mediated reduction chemistry previously reported for phosphine oxides, ${ }^{64}$ and helps to account for the low yield and poor selectivity of this reaction. Compound $\mathbf{8} \cdot \mathbf{O P P h}_{3}$ was, however, obtained cleanly from the single-step reaction of $\mathbf{I}^{\mathrm{Ca}}$ with two equivalents each of $\mathrm{Ph}_{3} \mathrm{SnH}$ and $\mathrm{Ph}_{3} \mathrm{PO}$ in $\mathrm{C}_{6} \mathrm{D}_{6}$. Although high solubility of the crystalline product obtained from this reaction provided a low, unoptimised isolated yield, it displayed identical NMR resonances to those described above.

Mindful of phosphine oxide reactivity towards reductive and/or nucleophilic alkaline-earth complexes, ${ }^{61,64}$ it was decided that 2,2,5,5-tetramethyltetrahydrofuran (TMTHF) would be a better choice of Lewis-base. Westerhausen and coworkers have recently reported the use of TMTHF to prepare monomeric amide complexes $\left[\mathrm{Ae}\left\{\mathrm{N}\left(\mathrm{SiMe}_{3}\right)_{2}\right\}_{2} \cdot \mathrm{TMTHF}\right](\mathrm{Ae}=$ $\mathrm{Mg}, \mathrm{Ca}, \mathrm{Sr}, \mathrm{Ba}$ ), in which the TMTHF ligand is highly labile in solution. ${ }^{65}$ We reasoned that, whilst coordination of TMTHF would encourage monomerisation, its relatively labile binding compared to more common bases such as THF or DMAP, might enhance the reactivity of the resultant calcium stannanide complex. Hence, $\mathbf{I}^{\mathrm{Ca}}$ was dissolved in $\mathrm{C}_{6} \mathrm{D}_{6}$ with two equivalents each of $\mathrm{Ph}_{3} \mathrm{Sn}-\mathrm{SnPh}_{3}$ and TMTHF (Scheme 6). Analysis of the crude reaction mixture by ${ }^{1} \mathrm{H}$ NMR spectroscopy showed complete conversion of the starting materials after two days at room temperature. A new product, 8.TMTHF, was characterised by a broadened resonance at $\delta 5.21 \mathrm{ppm}$ corresponding to the $\gamma$ - $\mathrm{CH}$ of the BDI ligand backbone. The ${ }^{119} \mathrm{Sn}\left\{{ }^{1} \mathrm{H}\right\}$ NMR spectrum comprised a resonance at $\delta$ $-170.6 \mathrm{ppm}$ in addition to a signal which was readily assigned as $\mathrm{Ph}_{4} \mathrm{Sn}$ at $\delta-126 \mathrm{ppm}$. Colourless block-like single crystals deposited from the reaction mixture overnight and were shown to be the monomeric TMTHF-solvated calcium stannanide, compound 8.TMTHF, by X-ray diffraction analysis (Fig. 2b). Compound 8.TMTHF could also be obtained by reacting $\mathbf{I}^{\text {Ca }}$ with two equivalents of $\mathrm{Ph}_{3} \mathrm{SnH}$ in toluene (Scheme 6). Organostannane redistribution to $\mathrm{Ph}_{4} \mathrm{Sn}$ was completely circumvented by use of a ten-fold excess of TMTHF, and 8.TMTHF was deposited as colourless crystals on standing at room temperature overnight in $68 \%$ yield.

Once crystallised, 8.TMTHF is sparingly soluble in aromatic solvents but is readily soluble in THF. The ${ }^{1} \mathrm{H}$ NMR spectrum in $\mathrm{d}_{8}$-THF displayed a single, well-defined BDI environment, while resonances observed at $\delta 1.80$ and $1.16 \mathrm{ppm}$ suggested displacement of TMTHF from the calcium centre by the NMR solvent. The resultant ${ }^{119} \mathrm{Sn}\left\{{ }^{1} \mathrm{H}\right\}$ chemical shift was also substantially perturbed with a single resonance appearing at $\delta$ $-137.3 \mathrm{ppm}$. Despite poor solubility, attempts to obtain NMR spectra of isolated and vacuum-dried crystals of 8.TMTHF in 
(a)

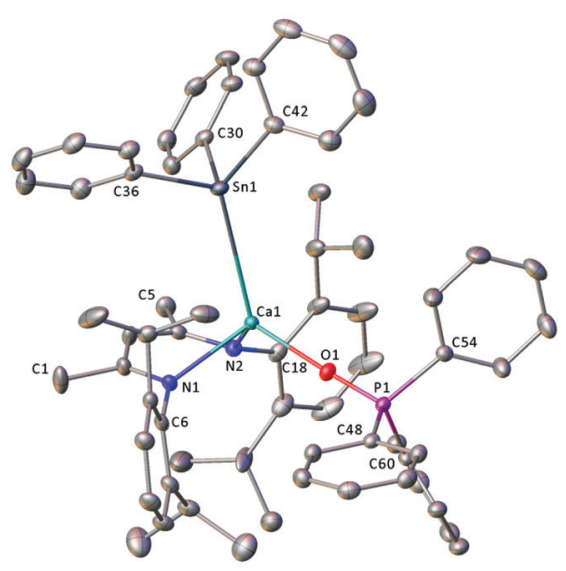

(b)

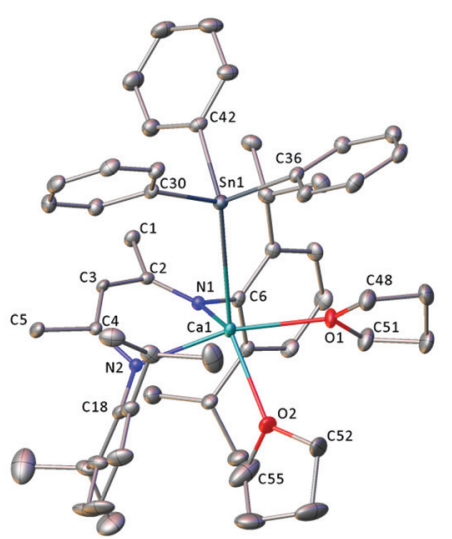

(c)
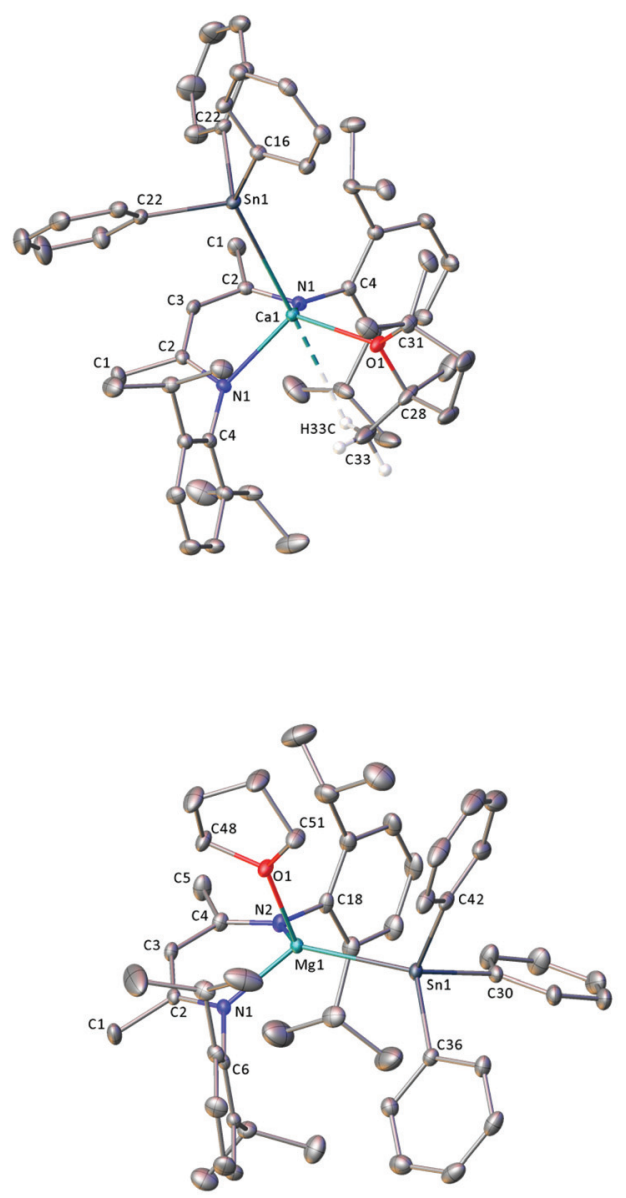

(d)

Fig. 2 X-ray crystal structures of (a) 8.0PPh atoms are omitted for clarity except for those bound to C33 in 8.TMTHF. Where disorder is present only the major component is shown.

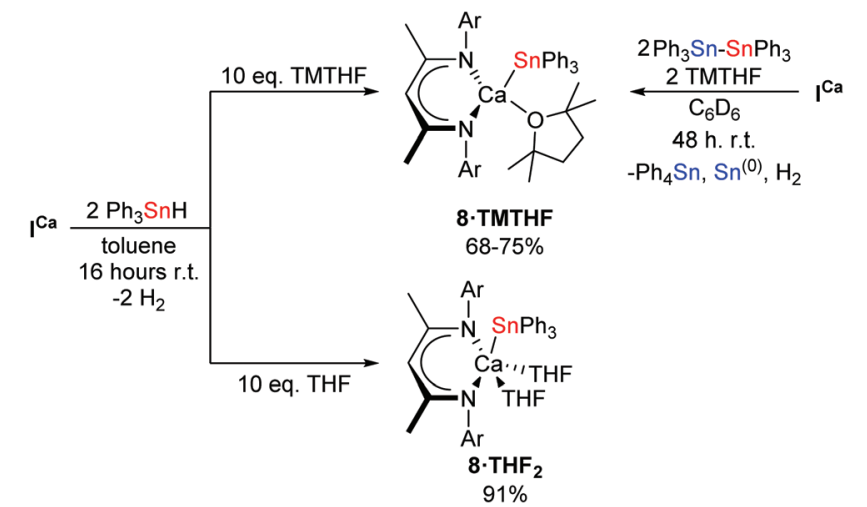

Scheme 6 Synthesis of 8.TMTHF and 8.THF . Ar $=2,6$-diisopropylphenyl.

$\mathrm{C}_{6} \mathrm{D}_{6}$ were successful, albeit the resonances were weak and broadened. Nevertheless, we were interested to find that two species were clearly discernible by ${ }^{1} \mathrm{H}$ NMR spectroscopy. Although both species were identifiable as 8.TMTHF by the BDI $\gamma$-CH resonance at $\delta 5.21 \mathrm{ppm}$ and the Lewis base-free compound, 4 ( $\delta 5.02 \mathrm{ppm}$ for $\gamma$-CH of the BDI backbone) ${ }^{42}$ their contrasting solubility in aromatic solvents prevented any confident, quantitative analysis of their relative abundance in solution. The apparent lability of TMTHF under vacuum was, however, further supported by the low relative intensity of its associated ${ }^{1} \mathrm{H}$ resonances when vacuum-dried samples were redissolved in $\mathrm{d}_{8}$-THF. In order to investigate the viability of 8.TMTHF as a convenient precursor to $\mathbf{4}$, therefore, isolated crystals were stirred in the solid state under vacuum at $80{ }^{\circ} \mathrm{C}$ for sixteen hours. The resultant pale-yellow powder was only partially soluble in $\mathrm{d}_{8}$-toluene and, although the relative ratio of the two species determined by integration of the ${ }^{1} \mathrm{H}$ NMR spectrum was increased in favour of $\mathbf{4}$, substantial quantities of 8.TMTHF remained. Both species could be clearly discerned in the resulting ${ }^{119} \mathrm{Sn}\left\{{ }^{1} \mathrm{H}\right\}$ NMR spectrum, which comprised two resonances at $\delta-160.5$ (4) and $-170.7 \mathrm{ppm}$ (8.TMTHF).

The solution-state behaviour of 8.TMTHF was also investigated by variable temperature ${ }^{1} \mathrm{H}$ NMR in $\mathrm{d}_{8}$-toluene. Whilst separate environments for $\mathbf{4}$ and 8.TMTHF could be discerned at $298 \mathrm{~K}$, the $\gamma$ - $\mathrm{CH}$ signals coalesced to a single broad resonance at $\delta 5.11 \mathrm{ppm}$ above $318 \mathrm{~K}$. Similarly, resonances 
assigned to free TMTHF experienced a pronounced and simultaneous upfield shift with increasing temperature. Although no more quantitative information could be extracted from these experiments, both of these observations suggest the establishment of a coordination-decoordination equilibrium when isolated 8.TMTHF samples are dissolved in arene solvents, facilitated by the lability of coordinated TMTHF.

The THF-solvated calcium hydride, $[(\mathrm{BDI}) \mathrm{CaH} \cdot \mathrm{THF}]_{2}$ $\left(\mathbf{I}^{\mathbf{C a}} \cdot \mathbf{T H F}_{2}\right)$ was also reacted with two equivalents of $\mathrm{Ph}_{3} \mathrm{SnH}$ under a ten-fold excess of THF in toluene. After stirring overnight at room temperature, volatiles were removed under vacuum to provide the bis-THF adduct, $\mathbf{8} \cdot \mathbf{T} \mathbf{H F}_{2}$, as a pale cream-coloured powder in high yield (Scheme 6). Its molecular structure (Fig. 2c) was determined by X-ray diffraction analysis performed on single crystals obtained by slow evaporation of a saturated toluene/THF solution. Compound $\mathbf{8} \cdot \mathbf{T H F}$ is readily soluble in aromatic solvents and displays a well-defined ${ }^{1} \mathrm{H}$ NMR spectrum in $\mathrm{C}_{6} \mathrm{D}_{6}$ or $\mathrm{d}_{8}$-toluene. The single ${ }^{119} \mathrm{Sn}$ environment resonates at $\delta-138.4 \mathrm{ppm}$ in $\mathrm{C}_{6} \mathrm{D}_{6}$. When dissolved in $\mathrm{d}_{8}$-THF, the ${ }^{1} \mathrm{H}$ and ${ }^{119} \mathrm{Sn}\left\{{ }^{1} \mathrm{H}\right\}$ NMR spectra of $\mathbf{8 \cdot \mathbf { T H F } _ { 2 }}$ were identical to that of 8.TMTHF in the same solvent, supporting the hypothesis that TMTHF is readily displaced from the calcium centre in THF-solution.

Whilst $\mathbf{I}^{\mathrm{Ca}}$ reacts rapidly with two equivalents of $\mathrm{Ph}_{3} \mathrm{SnH}$ to provide 3 , the magnesium congener, $[(\mathrm{BDI}) \mathrm{MgH}]_{2}\left(\mathbf{I}^{\mathbf{M g}}\right)$ reacts much more slowly. Although, approximately $50 \%$ of the initial $\mathrm{Ph}_{3} \mathrm{SnH}$ was observed to have redistributed to $\mathrm{Ph}_{4} \mathrm{Sn}$ after five days at room temperature (Scheme 7 ), the ${ }^{1} \mathrm{H}$ NMR spectrum showed no net consumption of $\mathbf{I}^{\mathbf{M g}}$. In addition, no other significant BDI- or Sn-containing products could be detected by either ${ }^{1} \mathrm{H}$ or ${ }^{119} \mathrm{Sn}\left\{{ }^{1} \mathrm{H}\right\}$ NMR spectroscopy. Repetition of the reaction in toluene with a 10 -fold excess of THF, however, not only suppressed organostannane redistribution, but also accelerated consumption of $\mathrm{Ph}_{3} \mathrm{SnH}$. The monomeric magnesium stannanide complex, 9.THF, was, thus, obtained in near quantitative yield as a colourless powder after stirring for 16 hours at room temperature and removal of volatiles under vacuum (Scheme 7). Single-crystals suitable for X-ray diffraction analysis were obtained by slow diffusion of hexane vapour into a THF solution at $-30{ }^{\circ} \mathrm{C}$, providing confirmation of the solidstate structure (Fig. 2d). Compound 9.THF is readily soluble in aromatic solvents and THF and, albeit the ${ }^{1} \mathrm{H}$ resonances associated with the iso-propyl resonances were substantially broadened in $\mathrm{C}_{6} \mathrm{D}_{6}$ at $25{ }^{\circ} \mathrm{C}$, both the ${ }^{1} \mathrm{H}$ and ${ }^{13} \mathrm{C}\left\{{ }^{1} \mathrm{H}\right\}$ NMR spectra were indicative of a single BDI-environment. Similarly, the ${ }^{119} \mathrm{Sn}\left\{{ }^{1} \mathrm{H}\right\}$ NMR spectrum displayed a single resonance at $\delta$ -155.4 ppm in $\mathrm{C}_{6} \mathrm{D}_{6}$.

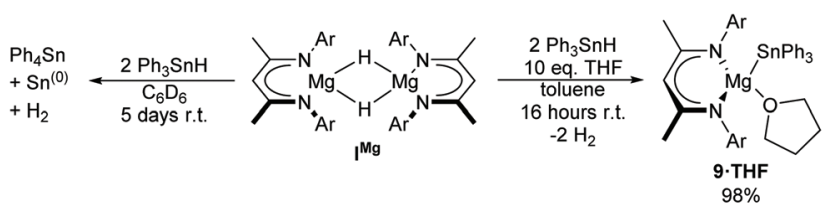

Scheme 7 Synthesis of 9-THF. Ar = 2,6-di-isopropylphenyl.
X-ray diffraction analysis of 8. $\mathrm{OPPh}_{3}, 8 \cdot \mathrm{THF}_{2}, 8 \cdot \mathrm{TMTHF}$ and 9.THF

Compounds 8. $\mathbf{O P P h} \mathbf{P h}_{3}, \mathbf{8} \cdot \mathbf{T H} \mathbf{H F}_{2}$ and $\mathbf{9} \cdot \mathbf{T H F}$ each crystallise in the monoclinic space group, $P 2_{1} / c$, whilst the crystal structure of 8.TMTHF adopts the $P 2_{1} / m$ space group (Fig. 2a-d; selected bond distances and angles are presented in Table 1). Whilst the geometries of the four-coordinate calcium centres in 8. $\mathbf{O P P h}_{3}$ and 8.TMTHF are best described as distorted tetrahedra, 9·THF adopts a near trigonal-pyramidal geometry, with the magnesium centre situated 0.557(1) A above an equatorial plane defined by the nitrogen and tin atoms $\left(\Sigma_{\text {angles }}=342^{\circ}\right)$. The geometry of the five-coordinate calcium centre in $\mathbf{8} \cdot \mathbf{T} \mathbf{H} \mathbf{F}_{\mathbf{2}}$ can be considered as a heavily distorted trigonal bipyramid, with the $\left[\mathrm{Ph}_{3} \mathrm{Sn}\right]^{-}$and one THF ligand in the axial positions and the BDI ligand and the second THF molecule occupying the equatorial sites. Compound 8.TMTHF is bisected through $\mathrm{C} 3$, the C16-C21 phenyl ring, and the furan ring by a mirror plane that is intrinsic to the space group, such that half a molecule is present per asymmetric unit. The methyl groups of the TMTHF ligand were disordered across the crystallographic mirror and a weak anagostic interaction was observed between one methyl group and the calcium centre. This is manifested by a H33C-Ca1 distance of 2.85(6) $\AA$, and the consequently contrasting Ca-O-C angles: Ca1-O1-C28 = 113.88(16) ${ }^{\circ}$, Ca1$\mathrm{O} 1-\mathrm{C} 31=135.75(16)^{\circ}$. The Ca-Sn bond lengths of compounds 8. $\mathbf{O P P h}_{3}, \mathbf{8 \cdot T M T H F}$ and $\mathbf{8} \cdot \mathbf{T H F}_{2}$ all lie within a narrow range established for compounds 3 (3.2137(4) $\AA$ ) and 4 (3.3221(6) $\AA$ ) and are comparable to the analogous distance in Westerhausen's calcium trimethylstannanide derivative (5, 3.2721(3) ̊). ${ }^{43}$ The phosphine-oxide adduct, 8.OPPh $\mathbf{O P}_{3}$, displays an apparently more compressed coordination sphere, with shorter $\mathrm{Ca}-\mathrm{Sn},-\mathrm{N}$, and $-\mathrm{O}$ bonds than the furan-coordinated analogues. As a likely result of the steric congestion imposed by the bulky BDI ligand on the relatively weakly Lewis-basic triphenylstannanide anion, the $\mathbf{M g}-\mathrm{Sn}$ bond of 9.THF is longer $(2.8340(6) \AA)$ than that of the $\left[\mathrm{Sn}\left(\mathrm{SiMe}_{3}\right)_{3}\right]^{-}$based complex, 6 $(2.817(1) \AA)$, the only other crystallographically characterised example of this type of bond in the literature. ${ }^{45}$ In the calcium complexes, the metal centres project by $1.266(2) \AA\left(\mathbf{8} \cdot \mathbf{T H F}_{2}\right)$, 1.449(2) $\AA$ (8-OPPh 3 ) and 1.575(2) $\AA$ (8·TMTHF) from the mean plane of the BDI ligand backbone, and the $\left[\mathrm{Ph}_{3} \mathrm{Sn}\right]^{-}$moiety is located above the BDI-ligand backbone. In contrast, the smaller ionic radius of magnesium results in a $0.742(2) \AA$ displacement of the metal centre from the BDI-plane in 9.THF, forcing the stannanide ligand away from the iso-propyl groups, and into the 'pocket' defined by the flanking Dipp groups of the BDI-ligand. The calcium complexes all display slightly compressed $\mathrm{C}-\mathrm{Sn}-\mathrm{C}$ angles, thus distorting the geometry of the otherwise tetrahedral tin centres. The Ca1-O1-P1 angle of $\mathbf{8} \cdot \mathbf{O P P h}_{3}$ is approaching linearity $\left(173.47(10)^{\circ}\right)$, whilst the $\mathrm{Ca}-\mathrm{O}$ and $\mathrm{O}-\mathrm{P}$ distances are similar to those of the alkyl-calcium $\mathrm{Ph}_{3} \mathrm{PO}$ adduct, $\left[\left(\mathrm{Ph}_{3} \mathrm{PO}\right)_{2} \mathrm{Ca}\left\{\mathrm{CH}\left(\mathrm{SiMe}_{3}\right)_{2}\right\}_{2}\right]$ previously reported by Hill et al. ${ }^{64}$

\section{Salt metathesis reactions with 8-TMTHF and 9.THF}

With a series of well-defined monomeric Ae-stannanide derivatives in hand, we undertook an initial exploration of their reac- 
Table 1 Selected bond lengths ( $(\AA)$ and angles $\left(^{\circ}\right)$ for compound 8.L and 9.THF

\begin{tabular}{|c|c|c|c|c|c|}
\hline Compound & 8.TMTHF & & $8 \cdot \mathrm{OPPh}_{3}$ & $8 \cdot \mathbf{T H F}_{2}$ & 9.THF \\
\hline Sn1-Ca1 & $3.2470(5)$ & Sn1-Ae1 & $3.2304(4)$ & $3.2951(5)$ & $2.8340(6)$ \\
\hline Sn1-C16 & $2.197(3)$ & Sn1-C30 & $2.195(2)$ & $2.200(2)$ & $2.184(2)$ \\
\hline \multirow[t]{2}{*}{ Sn1-C22 } & $2.203(2)$ & Sn1-C36 & $2.199(2)$ & $2.204(3)$ & $2.176(2)$ \\
\hline & & Sn1-C42 & $2.192(2)$ & $2.205(3)$ & $2.183(2)$ \\
\hline \multirow[t]{2}{*}{ Ca1-O1 } & $2.3768(19)$ & Ae1-O1 & $2.2020(15)$ & $2.3723(18)$ & $2.0513(15)$ \\
\hline & & Ae1-O2 & & $2.406(2)$ & \\
\hline \multirow[t]{6}{*}{ Ca1-N1 } & $2.3349(15)$ & Ae1-N1 & $2.3014(17)$ & $2.336(2)$ & $2.0485(17)$ \\
\hline & & Ae1-N2 & $2.3189(16)$ & $2.348(2)$ & $2.0449(18)$ \\
\hline & & P1-O1 & $1.5044(15)$ & & \\
\hline & & $\mathrm{P} 1-\mathrm{C} 48$ & $1.797(2)$ & & \\
\hline & & P1-C54 & $1.800(2)$ & & \\
\hline & & $\mathrm{P} 1-\mathrm{C} 60$ & $1.799(2)$ & & \\
\hline \multirow[t]{2}{*}{ C22-Sn1-Ca1 } & $112.60(5)$ & C30-Sn1-Ae1 & $105.87(5)$ & $116.46(7)$ & $117.77(6)$ \\
\hline & & C36-Sn1-Ae1 & $118.23(6)$ & $115.74(7)$ & $120.00(6)$ \\
\hline C22-Sn1-C22' & $99.37(11)$ & C30-Sn1-C36 & $99.65(8)$ & $102.12(10)$ & $100.80(8)$ \\
\hline C16-Sn1-C22 & $97.62(7)$ & C42-Sn1-C36 & $98.60(8)$ & $102.74(10)$ & $101.57(8)$ \\
\hline \multirow[t]{2}{*}{ C16-Sn1-Ca1 } & $131.74(8)$ & C42-Sn1-Ae1 & $128.90(6)$ & $121.44(7)$ & $113.02(5)$ \\
\hline & & C42-Sn1-C30 & $100.93(8)$ & $94.76(9)$ & $100.76(8)$ \\
\hline \multirow[t]{3}{*}{ O1-Ca1-Sn1 } & $109.60(5)$ & O1-Ae1-Sn1 & $122.09(4)$ & $89.97(5)$ & $105.21(5)$ \\
\hline & & $\mathrm{O} 1-\mathrm{Ae} 1-\mathrm{O} 2$ & & $75.66(8)$ & \\
\hline & & $\mathrm{O} 2-\mathrm{Ae} 1-\mathrm{Sn} 1$ & & $142.83(7)$ & \\
\hline \multirow[t]{4}{*}{ N1-Ca1-O1 } & $118.71(5)$ & O1-Ae1-N1 & $105.76(6)$ & $102.09(7)$ & $104.24(7)$ \\
\hline & & $\mathrm{N} 1-\mathrm{Ca} 1-\mathrm{O} 2$ & & 118.41(9) & \\
\hline & & O1-Ae1-N2 & $112.13(6)$ & $165.72(7)$ & $102.25(7)$ \\
\hline & & $\mathrm{N} 2-\mathrm{Ae} 1-\mathrm{O} 2$ & & $90.51(8)$ & \\
\hline N1-Ca1-Sn1 & $112.64(4)$ & N1-Ae1-Sn1 & $109.38(4)$ & $97.89(5)$ & $122.92(5)$ \\
\hline \multirow[t]{2}{*}{ N1-Ca1-N1' } & $82.33(8)$ & N1-Ae1-N2 & $81.07(6)$ & $81.14(7)$ & $93.52(7)$ \\
\hline & & N2-Ae1-Sn1 & $117.58(4)$ & $103.45(5)$ & $125.61(5)$ \\
\hline C28-O1-Ca1 & $113.88(16)$ & O1-P1-C48 & $110.55(9)$ & & \\
\hline \multirow[t]{6}{*}{ C31-O1-Ca1 } & $135.75(16)$ & O1-P1-C54 & $110.49(9)$ & & \\
\hline & & O1-P1-C60 & 111.32(9) & & \\
\hline & & C48-P1-C54 & 108.26(9) & & \\
\hline & & C48-P1-C60 & $110.27(9)$ & & \\
\hline & & C60-P1-C54 & $105.81(10)$ & & \\
\hline & & P1-O1-Ca1 & $173.47(10)$ & & \\
\hline
\end{tabular}

tivity. The highly ionic nature of the Ae-Sn bond suggests that they can be considered as hydrocarbon-soluble salts of the $\mathrm{Ph}_{3} \mathrm{Sn}^{-}$anion. As such, compounds 8.TMTHF and 9.THF were reacted with 0.5 equivalents of $t-\mathrm{Bu}_{2} \mathrm{SnCl}_{2}$ in $\mathrm{C}_{6} \mathrm{D}_{6}$ (Scheme 8). Both reactions provided a relatively clean ${ }^{1} \mathrm{H}$ NMR spectrum indicative of the formation of a single major BDI-containing product. A pair of resonances at $\delta-76.9$ and $-137.20 \mathrm{ppm}$ in the ${ }^{119} \mathrm{Sn}\left\{{ }^{1} \mathrm{H}\right\}$ NMR spectrum was consistent with formation of the alternating tristannane, $\mathrm{Ph}_{3} \mathrm{Sn}-\mathrm{Sn}(t-\mathrm{Bu})_{2}-\mathrm{SnPh}_{3}$ (11). The identity of this compound was confirmed by X-ray diffraction and NMR spectroscopic analysis performed on single crystals isolated by fractional recrystallisation of the crude product mixture from hexane/toluene. Unfortunately, a satisfactory sample of the calcium-containing by-product $\left(\mathbf{1 0}^{\mathrm{Ca}}\right)$ could not be isolated from the reaction involving 8-TMTHF. When 9.THF was used, however, colourless crystalline blocks were deposited from the reaction mixture and identified as the known chloride complex, $[(\mathrm{BDI}) \mathrm{Mg}(\mu-\mathrm{Cl})]_{2} \mathbf{1 0}^{\mathbf{M g}}$, by comparison to the published unit cell parameters and NMR spectra. ${ }^{66}$

Compound 11 was first isolated in 33\% yield (versus 78\% in the current work) by Adams and Dräger in 1987 and synthesised by salt metathesis of the lithiated precursor, $\mathrm{Ph}_{3} \mathrm{SnLi}$, with $t-\mathrm{Bu}_{2} \mathrm{SnI}_{2}$ in THF and/or toluene. ${ }^{67}$ Notably, although selectivity could be improved by variation of reaction stoichiometry, solvent polarity and concentration, this earlier approach yielded a mixture of $\mathrm{Ph}_{3} \mathrm{Sn}$-capped tetra-, penta-, and hexastannanes such that the published crystal structure of $\mathbf{1 1}$ was as a component of a co-crystal with the tetrastannane, $\mathrm{Ph}_{3} \mathrm{Sn}-$

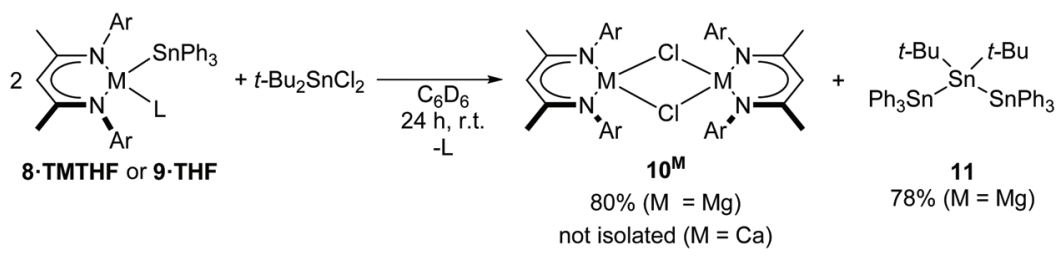

Scheme 8 Synthesis of alternating tristannane 11 by salt metathesis of Ae-stannanides and $t-\mathrm{Bu}_{2} \mathrm{SnCl}_{2} . \mathrm{Ar}=2,6-\mathrm{diisopropylphenyl}$, $\mathrm{L}=\mathrm{THF}$, TMTHF. 
$\mathrm{Sn}(t-\mathrm{Bu})_{2}-\mathrm{Sn}(t-\mathrm{Bu})_{2}-\mathrm{SnPh}_{3}$. For completeness, therefore, the crystal structure of the pure tristannane, 11, is included in the ESI (Fig. S1 $\dagger$ ). This reaction presents 8.TMTHF and 9.THF as promising alternatives to group 1 metallated organostannanes in salt metathesis reactions. ${ }^{68-71}$

\section{Insertion/nucleophilic addition of Ae-Sn bonds to $N, N^{\prime}$-di-iso- propylcarbodiimide}

As an initial assay of the potential utility of BDI-Ae stannanides to engage in catalytically relevant insertion reactions with

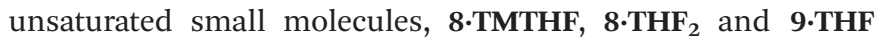
were reacted with one equivalent of $N, N^{\prime}$-di-iso-propylcarbodiimide (DIC) in $\mathrm{C}_{6} \mathrm{D}_{6}$ (Scheme 9). To the best of our knowledge, the resultant compounds provide the first reported $C$-organostannyl analogues of the ubiquitous amidinate class of $N, N$-donor anions. Compound 9.THF required 48 hours to cleanly convert DIC into the stannyl-amidinate complex, 12, at room temperature. Compound $\mathbf{1 2}$ was characterised by an upfield-shifted resonance at $\delta-186.9 \mathrm{ppm}$ in the ${ }^{119} \mathrm{Sn}\left\{{ }^{1} \mathrm{H}\right\}$ NMR spectrum and a characteristic resonance at $\delta 181.9 \mathrm{ppm}$ in the ${ }^{13} \mathrm{C}\left\{{ }^{1} \mathrm{H}\right\}$ NMR spectrum, corresponding to the central carbon atom of the $\mathrm{Mg}$-ligated stannyl-aminidate ligand. The ${ }^{1} \mathrm{H}$ NMR spectrum was indicative of a single, symmetrical BDI environment, with equivalent $N$-iso-propyl environments and characteristic $\mathrm{Sn} P h_{3}$ resonances with ${ }^{119 / 117} \mathrm{Sn}$ satellites. THF was absent from the isolated product, which was obtained as a colourless powder by removal of volatiles under vacuum and which could be crystallised from methylcyclohexane at $-30{ }^{\circ} \mathrm{C}$. The resultant colourless blocks were subjected to single-crystal $\mathrm{X}$-ray diffraction analysis to provide the molecular structure of compound 12 (Fig. 3).

The calcium complexes were more reactive towards DIC compared to 9.THF. Compound 8-TMTHF provided a clear, colourless solution of the calcium stannyl-amidinate, 13.TMTHF, after 60 minutes of sonication at room temperature. A further reaction at room temperature for 16 hours also provided quantitative spectroscopic conversion to 13·TMTHF, and 13.THF was obtained in a similar manner from $\mathbf{8} \cdot \mathbf{T H} \mathbf{H F}_{2}$ (Scheme 9). Compounds 13.TMTHF and 13.THF were isolated as colourless powders after removing volatiles from the reaction mixture and displayed similar ${ }^{1} \mathrm{H},{ }^{13} \mathrm{C}\left\{{ }^{1} \mathrm{H}\right\}$, and ${ }^{119} \mathrm{Sn}\left\{{ }^{1} \mathrm{H}\right\}$ NMR spectra to 12. Compared to 12 , the ${ }^{119} \mathrm{Sn}\left\{{ }^{1} \mathrm{H}\right\}$ resonances of 13.TMTHF
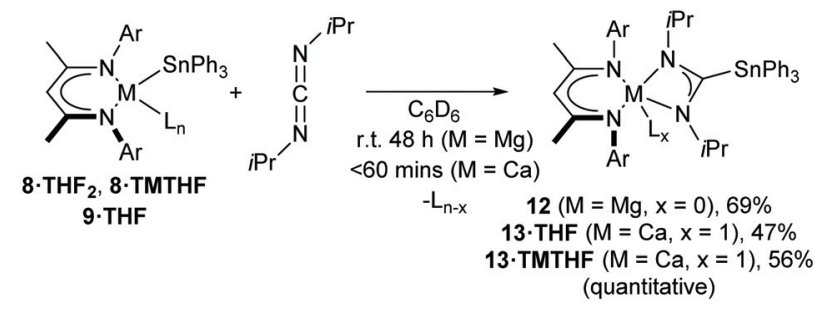

Scheme 9 Synthesis of stannylamidinates 12, 13.THF and 13.TMTHF Ar = 2,6-di-isopropylphenyl, $L=$ THF, TMTHF. Yields refer to unoptimised isolated yield, with quantitative spectroscopic conversion determined by ${ }^{1} \mathrm{H}$ NMR spectroscopy. Ar = 2,6-di-isopropylphenyl.

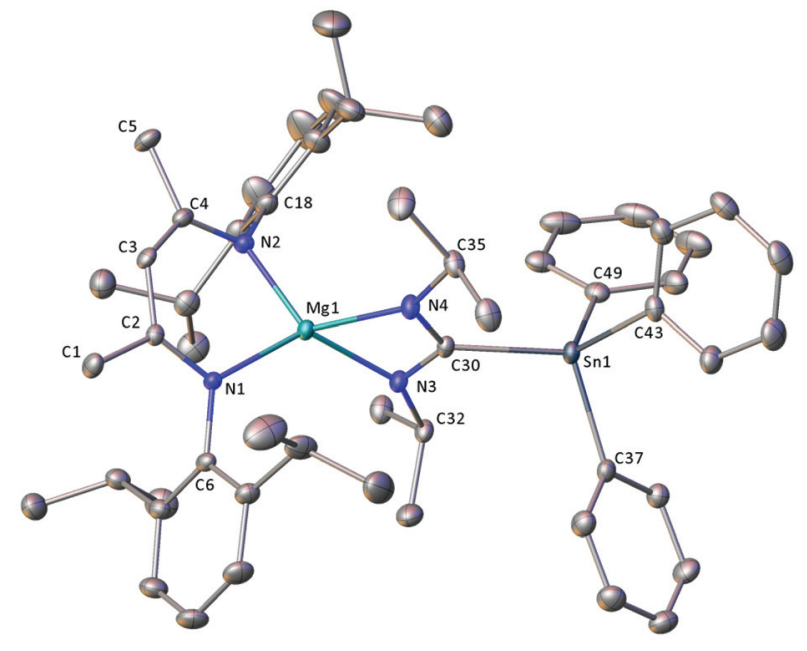

Fig. 3 X-ray crystal structure of compound 12. Ellipsoids are shown at the $30 \%$ probability level and hydrogen atoms are omitted for clarity. The crystal structure contains two methylcyclohexane molecules per unit cell, which were heavily disordered across inversion centres and treated using a solvent mask algorithm. Selected bond lengths $(\AA)$ and angles ( ${ }^{\circ}$ ): Sn1-C30 2.2030(14), Sn1-C37 2.1420(16), Sn1-C43 2.1524, Sn1-C49 2.1409(16), Mg1-N1 2.0328(13), Mg1-N2 2.0446(13), Mg1-N3 2.0456(13), Mg1-N4 2.0763(13), N3-C30 1.3353(19), N4-C30 1.3311(19), C38-Sn1-C30 109.38(6), C37-Sn1-C43 100.64(6), C43-Sn1-C30 123.56(6), C49-Sn1-C30 107.77(6), C49-Sn1-C37 110.98(6), C49-Sn1C43 104.12(6), N1-Mg1-N2 94.98(5), N1-Mg1-N3 128.51(5), N1-Mg1N4 125.70(5), N2-Mg1-N3 122.53(6), N2-Mg1-N4 121.01(6), N3-Mg1N4 66.12(5), N3-C30-Sn1 119.36(10), N4-C30-Sn1 125.54(11), N4C30-N3 114.99(13).

and 13.THF exhibited slightly upfield shifts to $\delta-193.8$ and -196.1 ppm, respectively, whilst the stannyl-amidinate 'backbone' carbon nuclei resonated at $\delta 179.1$ and $177.1 \mathrm{ppm}$ in the corresponding ${ }^{13} \mathrm{C}\left\{{ }^{1} \mathrm{H}\right\}$ NMR spectra. The ${ }^{119} \mathrm{Sn}$ and ${ }^{117} \mathrm{Sn}$ satellites could also be clearly discerned for the tin-bonded amidinate ${ }^{13} \mathrm{C}$ resonance of $\mathbf{1 3}$-TMTHF to provide coupling constants of ${ }^{1} J\left({ }^{119} \mathrm{Sn}\right)=360.4 \mathrm{~Hz},{ }^{1} J\left({ }^{117} \mathrm{Sn}\right)=344.7 \mathrm{~Hz}$. The BDI and stannyl-amidinate ligands of both complexes display a set of resonances indicative of high symmetry and, in contrast to $\mathbf{1 2}$, the presence of a single coordinated TMTHF or THF was clearly discerned by ${ }^{1} \mathrm{H}$ NMR spectroscopy. Although attempts to acquire single crystals of 13-TMTHF were unsuccessful, colourless plate-like single crystals suitable for X-ray analysis of 13.THF were obtained by cooling a hexane/methylcyclohexane solution to $-30^{\circ} \mathrm{C}$.

Compound 12 crystallises in the monoclinic space group, $P 2_{1} / c$, with one molecule of the magnesium complex and one disordered solvent region, equating to two methylcylohexane molecules, per unit cell. The solid state structure of 12 (Fig. 3) consists of a four-coordinate distorted tetrahedral magnesium centre, bonded to a BDI ligand via $\mathrm{N} 1$ and $\mathrm{N} 2$, and to a stannyl-amidinate ligand via N3 and N4. Although the $\mathrm{Mg}-\mathrm{N}$ bond distances are all of a similar length, the magnesium centre is co-planar to the latter ligand but projects out of the mean N1-C2-C3-C4-N2 plane of the BDI ligand by $0.7483(16)$ $\AA$. The two bidentate ligands are effectively perpendicular, 
such that the angle between the mean planes defined by N1Mg1-N2 and N3-Mg1-N4-C30, is 90.47(6) ${ }^{\circ}$. Although no directly analogous stannyl-amidinate ligands have been reported previously, the $\mathrm{C} 30-\mathrm{Sn} 1$ bond length is unremarkable (2.2030(14) A). The C30-N3 and C30-N4 bond lengths (1.3353 (19), 1.3311(19) A) are slightly longer, and the N3-C30-N4 angle $\left(114.1(11)^{\circ}\right)$ is slightly more acute, than those previously reported in homo- and heteroleptic $N, N^{\prime}$-di-iso-propylformamidinate calcium complexes (ca. 1.28(3)-1.328(6) ̊, 118.6(4)$\left.121.3(2)^{\circ}\right) .^{72,73}$

Compound 13.THF crystallised in the monoclinic $C c$ space group and, unusually, contains four crystallographically independent molecules per unit cell (Fig. S2 $\dagger$ ). Because of this, and a fall-off in diffraction intensity at higher Bragg angles arising from the thin plate-like morphology of the crystal, a detailed discussion of the structure is unwarranted. The gross features of the compound are, however, unambiguous and the four molecules display only minor structural differences. The X-ray crystal structure of the Ca1/Sn1-containing molecule is shown in Fig. 4. The BDI, stannyl-amidinate and THF ligands are arranged about the five-coordinate calcium centre such that $\mathrm{N} 1, \mathrm{~N} 2$, and N3 lie in an approximate equatorial plane, with O1 located axially. The two chelating ligands are arranged in a similar way to those in 12, with an average twist angle of approximately $93^{\circ}$ between the mean planes defined by $\mathrm{N}^{\mathrm{BDI}}$ $\mathrm{Ca}-\mathrm{N}^{\mathrm{BDI}}$, and $\mathrm{N}^{\mathrm{am}}-\mathrm{Mg} 1-\mathrm{N}^{\mathrm{am}}-\mathrm{C}^{\mathrm{am}}$, respectively. Significant variations in the structural metrics pertaining to the stannylamidinate ligands of 12 and 13.THF were not unambiguously discernible, but the larger ionic radius and higher coordination number of calcium results in displacement of the metal centre by approximately $2.5 \AA$ from the mean plane of the BDI ligand backbone.

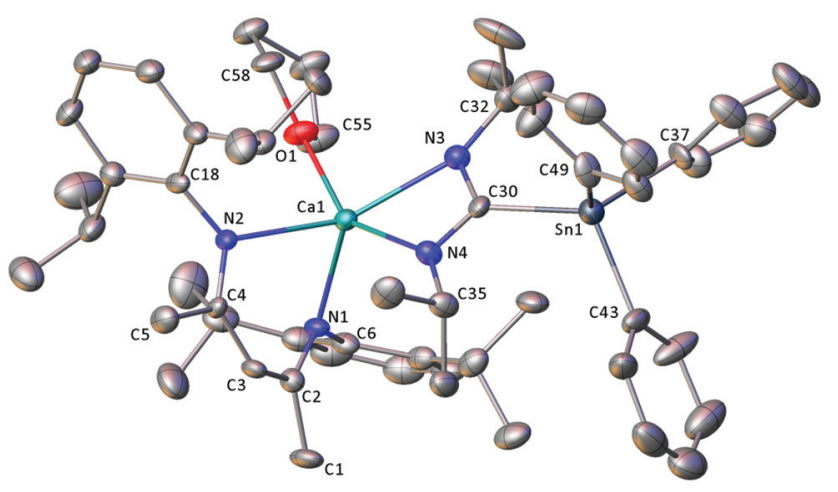

Fig. 4 X-ray crystal structure of compound 13-THF. Ellipsoids are shown at the $30 \%$ probability level and hydrogen atoms are omitted for clarity. Only one of the four crystallographically independent molecules present in the unit cell is shown. Selected bond lengths $(\AA)$ and angles ('): Sn1-C30 2.214(12), Sn1-C37 2.165(10), Sn1-C43 2.167(13), Sn1-C49 2.094(13), Ca1-O1 2.377(10), Ca1-N1 2.382(10), Ca1-N2 2.341(10), Ca1N3 2.373(11), Ca1-N4 2.377(11), N3-C30 1.380(17), N4-C30 1.311(16), C37-Sn1-C30 120.5(5), C37-Sn1-C43 100.1(5), C43-Sn1-C30 113.7(5), C49-Sn1-C30 107.4(5), C49-Sn1-C43 107.7(6), O1-Ca1-N1 97.9(4), N2-Ca1-O1 89.8(4), N2-Ca1-N1 80.2(4), N2-Ca1-N3 146.0(4), N2Ca1-N4 108.9(4), N3-Ca1-O1 150.4(4), N4-Ca1-N1 107.6(4), N3C30-Sn1 123.7(13), N4-C30-Sn1 121.2(9), N4-C30-N3 114.1(11).

\section{Conclusions}

In conclusion, dimeric calcium and magnesium hydrides $\mathbf{I}^{\mathrm{Ca}}$, $\mathbf{I}^{\mathbf{C a}} \cdot \mathbf{T H F}_{2}$, and $\mathbf{I}^{\mathbf{M g}}$ deprotonate triphenylstannane in the presence of an excess of coordinating Lewis base to provide clean access to well-defined monomeric Ae-stannanide complexes in good yield. Calcium stannanide complexes are also accessible through distannane heterolysis by nucleophilic attack of a calcium hydride. A preliminary exploration of the reactivity arising from the resultant compounds demonstrates their potential as well-defined, soluble sources of the $\left[\mathrm{Ph}_{3} \mathrm{Sn}\right]^{-}$ anion in salt metathesis and nucleophilic addition reactions. Further work continues to explore the nature and reactivity of bonds between heavier p-block elements and the heavier alkaline earths.

\section{Conflicts of interest}

There are no conflicts to declare.

\section{Acknowledgements}

Financial support was provided by the EPSRC through grant numbers EP/N014456/1, EP/R020752/1, and the EPSRC Centre for Doctoral Training in Catalysis (EP/L016443/1). This research made use of the Balena High Performance Computing (HPC) Service at the University of Bath. I. M. thanks the University of Bristol for support and the Canadian Government for a Canada 150 Research Chair.

\section{Notes and references}

1 S. Harder, Chem. Rev., 2010, 110, 3852-3876.

2 M. S. Hill, D. J. Liptrot and C. Weetman, Chem. Soc. Rev., 2016, 45, 972-988.

3 S. Hong and T. J. Marks, Acc. Chem. Res., 2004, 37, 673-686.

4 J. F. Dunne, S. R. Neal, J. Engelkemier, A. Ellern and A. D. Sadow, J. Am. Chem. Soc., 2011, 133, 16782-16785.

5 C. Bellini, J.-F. Carpentier, S. Tobisch and Y. Sarazin, Angew. Chem., Int. Ed., 2015, 54, 7679-7683.

6 C. Bellini, V. Dorcet, J. F. Carpentier, S. Tobisch and Y. Sarazin, Chem. - Eur. J., 2016, 22, 4564-4583.

7 E. Le Coz, Z. Zhang, T. Roisnel, L. Cavallo, L. Falivene, J. F. Carpentier and Y. Sarazin, Chem. - Eur. J., 2020, 26, 3535-3544.

8 A. C. A. Ried, L. J. Taylor, A. M. Geer, H. E. L. Williams, W. Lewis, A. J. Blake and D. L. Kays, Chem. - Eur. J., 2019, 25, 6840-6846.

9 F. Buch and S. Harder, Organometallics, 2007, 26, 51325135.

10 M. S. Hill, D. J. Liptrot, D. J. MacDougall, M. F. Mahon and T. P. Robinson, Chem. Sci., 2013, 4, 4212-4222.

11 C. Bellini, V. Dorcet, J. F. Carpentier, S. Tobisch and Y. Sarazin, Chem. - Eur. J., 2016, 22, 4564-4583. 
12 A. Baishya, T. Peddarao and S. Nembenna, Dalton Trans., 2017, 46, 5880-5887.

13 E. Le Coz, V. Dorcet, T. Roisnel, S. Tobisch, J. F. Carpentier and Y. Sarazin, Angew. Chem., Int. Ed., 2018, 57, 1174711751.

14 E. Le Coz, S. Kahlal, J.-Y. Saillard, T. Roisnel, V. Dorcet, J.-F. Carpentier and Y. Sarazin, Chem. - Eur. J., 2019, 25, 13509-13513.

15 L. J. Morris, M. S. Hill, M. F. Mahon, I. Manners, F. S. McMenamy and G. R. Whittell, Chem. - Eur. J., 2020, 26, 2954-2966.

16 M. R. Crimmin, I. J. Casely and M. S. Hill, J. Am. Chem. Soc., 2005, 127, 2042-2043.

17 M. R. Crimmin, A. G. M. Barrett, M. S. Hill, P. B. Hitchcock and P. A. Procopiou, Organometallics, 2007, 26, 29532956.

18 M. R. Crimmin, A. G. M. Barrett, M. S. Hill, P. B. Hitchcock and P. A. Procopiou, Organometallics, 2008, 27, 497-499.

19 C. Weetman, M. D. Anker, M. Arrowsmith, M. S. Hill, G. Kociok-Kohn, D. J. Liptrot and M. F. Mahon, Chem. Sci., 2016, 7, 628-641.

20 F. Buch, H. Brettar and S. Harder, Angew. Chem., Int. Ed., 2006, 45, 2741-2745.

21 V. Leich, T. P. Spaniol, L. Maron and J. Okuda, Chem. Commun., 2014, 50, 2311-2314.

22 L. Garcia, C. Dinoi, M. F. Mahon, L. Maron and M. S. Hill, Chem. Sci., 2019, 10, 8108-8118.

23 D. Schuhknecht, T. P. Spaniol, L. Maron and J. Okuda, Angew. Chem., 2020, 59, 310-314.

24 D. Schuhknecht, C. Lhotzky, T. P. Spaniol, L. Maron and J. Okuda, Angew. Chem., Int. Ed., 2017, 56, 12367-12371.

25 (a) A. S. S. Wilson, C. Dinoi, M. S. Hill, M. F. Mahon and L. Maron, Angew. Chem., Int. Ed., 2018, 57, 15500-15504; (b) M. S. Hill, M. F. Mahon, A. S. S. Wilson, C. Dinoi, L. Maron and E. Richards, Chem. Commun., 2019, 55, 57325735; (c) A. S. S. Wilson, C. Dinoi, M. S. Hill, M. F. Mahon, L. Maron and E. Richards, Angew. Chem., 2020, 59, 12321237.

26 H. Bauer, M. Alonso, C. Fischer, B. Rosch, H. Elsen and S. Harder, Angew. Chem., Int. Ed., 2018, 57, 15177-15182.

27 D. J. Liptrot, M. Arrowsmith, A. L. Colebatch, T. J. Hadlington, M. S. Hill, G. Kociok-Köhn and M. F. Mahon, Angew. Chem., Int. Ed., 2015, 54, 1528015283.

28 N. A. Rajabi, C. L. McMullin and M. S. Hill, unpublished results.

29 A.-F. Pécharman, A. L. Colebatch, M. S. Hill, C. L. McMullin, M. F. Mahon and C. Weetman, Nat. Commun., 2017, 8, 15022.

30 W. Caseri, Chem. Soc. Rev., 2016, 45, 5187-5199.

31 M. Trummer, F. Choffat, P. Smith and W. Caseri, Macromol. Rapid Commun., 2012, 33, 448-460.

32 P. Espinet and A. M. Echavarren, Angew. Chem., Int. Ed., 2004, 43, 4704-4734.

33 M. M. Heravi and L. Mohammadkhani, J. Organomet. Chem., 2018, 869, 106-200.
34 C. Tamborski and E. J. Soloski, J. Am. Chem. Soc., 1961, 83, 3734-3734.

35 H. M. J. C. Creemers, J. G. Noltes and G. J. M. Vanderke, J. Organomet. Chem., 1968, 14, 217-221.

36 J. C. Lahournere and J. Valade, J. Organomet. Chem., 1970, 22, C3-C4.

37 M. Westerhausen and T. Hildenbrand, J. Organomet. Chem., 1991, 411, 1-17.

38 R. Hummeltenberg, K. Jurkschat and F. Uhlig, Phosphorus, Sulfur Silicon Relat. Elem., 1997, 123, 255-261.

39 C. Kayser, R. Klassen, M. Schurmann and F. Uhlig, J. Organomet. Chem., 1998, 556, 165-167.

40 U. Hermann, M. Schurmann and F. Uhlig, J. Organomet. Chem., 1999, 585, 211-214.

41 U. Englich, K. Ruhlandt-Senge and F. Uhlig, J. Organomet. Chem., 2000, 613, 139-147.

42 L. J. Morris, M. S. Hill, I. Manners, C. L. McMullin, M. F. Mahon and N. A. Rajabi, Chem. Commun., 2019, 55, 12964-12967.

43 M. Westerhausen, Angew. Chem., Int. Ed. Engl., 1994, 33, 1493-1495.

44 R. Fischer, J. Baumgartner, C. Marschner and F. Uhlig, Inorg. Chim. Acta, 2005, 358, 3174-3182.

45 D. Matioszek, N. Katir, S. Ladeira and A. Castel, Organometallics, 2011, 30, 2230-2235.

46 P. M. Chapple, S. Kahlal, J. Cartron, T. Roisnel, V. Dorcet, M. Cordier, J.-Y. Saillard, J.-F. Carpentier and Y. Sarazin, Angew. Chem., Int. Ed., 2020, 59, 9120-9126.

47 S. K. Sur and J. P. Colpa, Organometallics, 1989, 8, 27492751.

48 W. P. Neumann, H. Hillgartner, K. M. Baines, R. Dicke, K. Vorspohl, U. Kobs and U. Nussbeutel, Tetrahedron, 1989, 45, 951-960.

49 T. N. Mitchell, K. Kwetkat, D. Rutschow and U. Schneider, Tetrahedron, 1989, 45, 969-978.

50 T. N. Mitchell, J. Organomet. Chem., 1986, 304, 1-16.

51 T. N. Mitchell, A. Amamria, H. Killing and D. Rutschow, J. Organomet. Chem., 1986, 304, 257-265.

52 A. Khan, A. J. Lough, R. A. Gossage and D. A. Foucher, Dalton Trans., 2013, 42, 2469-2476.

53 T. N. Mitchell, A. Amamria, H. Killing and D. Rutschow, J. Organomet. Chem., 1983, 241, C45-C47.

54 H. Yoshida, A. Shinke and K. Takaki, Chem. Commun., 2013, 49, 11671-11673.

55 J. S. Stehouwer, N. Jarkas, F. Zeng, R. J. Voll, L. Williams, V. M. Camp, E. J. Malveaux, J. R. Votaw, L. Howell, M. J. Owens and M. M. Goodman, J. Med. Chem., 2008, 51, 7788-7799.

56 M. S. Alnajjar and H. G. Kuivila, J. Am. Chem. Soc., 1985, 107, 416-423.

57 B. Wrackmeyer, Annu. Rep. NMR Spectrosc., 1999, 38, 203264.

58 S. Harder, Organometallics, 2002, 21, 3782-3787.

59 G. M. Allan, R. A. Howie, J. N. Low, J. M. S. Skakle, J. L. Wardell and S. Wardell, Polyhedron, 2006, 25, 695-701. 
60 S. J. Bonyhady, C. Jones, S. Nembenna, A. Stasch, A. J. Edwards and G. J. McIntyre, Chem. - Eur. J., 2010, 16, 938-955.

61 A.-F. Pécharman, N. A. Rajabi, M. S. Hill, C. L. McMullin and M. F. Mahon, Chem. Commun., 2019, 55, 9035-9038.

62 A. C. T. Kuate, R. A. Lalancette, T. Bannenberg and F. Jäkle, Angew. Chem., Int. Ed., 2018, 57, 6552-6557.

63 J. W. Chen, D. A. M. Parra, R. A. Lalancette and F. Jäkle, Angew. Chem., Int. Ed., 2015, 54, 10202-10205.

64 M. S. Hill, M. F. Mahon and T. P. Robinson, Chem. Commun., 2010, 46, 2498-2500.

65 S. Krieck, P. Schuler, H. Gorls and M. Westerhausen, Inorg. Chem., 2018, 57, 13937-13943.

66 A. P. Dove, V. C. Gibson, P. Hormnirun, E. L. Marshall, J. A. Segal, A. J. P. White and D. J. Williams, Dalton Trans., 2003, 3088-3097.
67 S. Adams and M. Dräger, Angew. Chem., Int. Ed. Engl., 1987, 26, 1255-1256.

68 S. Adams and M. Dräger, J. Organomet. Chem., 1987, 323, 11-20.

69 D. Reed, D. Stalke and D. S. Wright, Angew. Chem., Int. Ed. Engl., 1991, 30, 1459-1460.

70 P. B. Hitchcock, M. F. Lappert, G. A. Lawless and B. Royo, J. Chem. Soc., Chem. Commun., 1993, 554-555.

71 T. Schollmeier, U. Englich, R. Fischer, I. Prass, K. Ruhlandt, M. Schurmann and F. Uhlig, Z. Naturforsch., B: J. Chem. Sci., 2004, 59, 1462-1470.

72 S. B. Kim, C. X. Yang, T. Powers, L. M. Davis, X. B. Lou and R. G. Gordon, Angew. Chem., Int. Ed., 2016, 55, 1022810233.

73 J. Dyall, M. S. Hill, M. F. Mahon, L. Teh and A. S. S. Wilson, Dalton Trans., 2019, 48, 4248-4254. 